2011s-70

\title{
Analyzing Economic Effects of Extreme Events using Debit and Payments System Data
}

\author{
John W. Galbraith, Greg Tkacz
}

\begin{tabular}{c}
\hline Série Scientifique \\
Scientific Series
\end{tabular}

Montréal

Novembre 2011

C 2011 John W. Galbraith, Greg Tkacz. Tous droits réservés. All rights reserved. Reproduction partielle permise avec citation du document source, incluant la notice (C).

Short sections may be quoted without explicit permission, if full credit, including (C) notice, is given to the source.
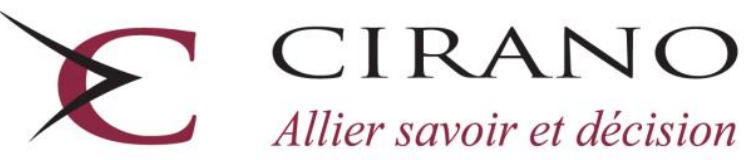

Allier savoir et décision

Centre interuniversitaire de recherche en analyse des organisations 


\section{CIRANO}

Le CIRANO est un organisme sans but lucratif constitué en vertu de la Loi des compagnies du Québec. Le financement de son infrastructure et de ses activités de recherche provient des cotisations de ses organisations-membres, d'une subvention d'infrastructure du Ministère du Développement économique et régional et de la Recherche, de même que des subventions et mandats obtenus par ses équipes de recherche.

CIRANO is a private non-profit organization incorporated under the Québec Companies Act. Its infrastructure and research activities are funded through fees paid by member organizations, an infrastructure grant from the Ministère du Développement économique et régional et de la Recherche, and grants and research mandates obtained by its research teams.

\section{Les partenaires du CIRANO}

\section{Partenaire majeur}

Ministère du Développement économique, de l'Innovation et de l'Exportation

\section{Partenaires corporatifs}

Autorité des marchés financiers

Banque de développement du Canada

Banque du Canada

Banque Laurentienne du Canada

Banque Nationale du Canada

Banque Royale du Canada

Banque Scotia

Bell Canada

BMO Groupe financier

Caisse de dépôt et placement du Québec

\section{CSST}

Fédération des caisses Desjardins du Québec

Financière Sun Life, Québec

Gaz Métro

Hydro-Québec

Industrie Canada

Investissements PSP

Ministère des Finances du Québec

Power Corporation du Canada

Rio Tinto Alcan

State Street Global Advisors

Transat A.T.

Ville de Montréal

\section{Partenaires universitaires}

École Polytechnique de Montréal

HEC Montréal

McGill University

Université Concordia

Université de Montréal

Université de Sherbrooke

Université du Québec

Université du Québec à Montréal

Université Laval

Le CIRANO collabore avec de nombreux centres et chaires de recherche universitaires dont on peut consulter la liste sur son site web.

Les cahiers de la série scientifique (CS) visent à rendre accessibles des résultats de recherche effectuée au CIRANO afin de susciter échanges et commentaires. Ces cahiers sont écrits dans le style des publications scientifiques. Les idées et les opinions émises sont sous l'unique responsabilité des auteurs et ne représentent pas nécessairement les positions du CIRANO ou de ses partenaires.

This paper presents research carried out at CIRANO and aims at encouraging discussion and comment. The observations and viewpoints expressed are the sole responsibility of the authors. They do not necessarily represent positions of CIRANO or its partners. 


\title{
Analyzing Economic Effects of Extreme Events using Debit and Payments System Data
}

\author{
John W. Galbraith ${ }^{\dagger}$, Greg Tkacz,
}

\begin{abstract}
Résumé / Abstract
This paper uses payments system data to study the impact on personal consumption expenditure, and therefore on economic activity, of occasional extreme events. The usual quarterly data supplied by central statistical agencies are of little use to policy makers for monitoring effects of transitory events, as the impacts of events lasting a few days or weeks may be obscured in time-aggregated data. However, technological advances of the past several years have resulted in new high-frequency data sources that could potentially provide more accurate and timely information on economic activity. Here we use daily Canadian debit transaction volume data, and business-day (five times per week) debit and check transaction volume and value data, to investigate the impact on consumer expenditure of several extreme events: the September 112001 terrorist attacks, the SARS epidemic in the spring of 2003, and the August 2003 electrical blackout. Contrary to initial perceptions of these events, we find only small and transitory effects.
\end{abstract}

Mots clés/Keywords: debit card transactions, macroeconomic monitoring, real-time data

Codes JEL : E21, G21

\footnotetext{
* We thank the Fonds québécois de la recherche sur la société et la culture (FQRSC), the Social Sciences and Humanities Research Council of Canada (SSHRC) and CIRANO (Centre Interuniversitaire de recherche en analyse des organisations) for support of this research, and the Interac Organization and Canadian Payments Association for generously providing data.

${ }^{\dagger}$ Corresponding author: john.galbraith@ @cgill.ca, tel. (514) 3984400.

${ }^{\ddagger}$ Department of Economics, St. Francis Xavier University.
} 


\section{Introduction}

Policy makers may be required to act in cases of unusual, extreme events in order to minimize their impacts on the economy. For this purpose they need some estimate of the severity of an event's effect on the economy in order to determine an appropriate policy response. However, although some indicators of aggregate economic activity are available monthly, key measures such as gross domestic product are produced at a quarterly frequency and are released with some delay. As a result, the short-term impacts of even quite large economic events are undetectable, being obscured by aggregation over time and geographical regions. For example, Hurricane Katrina was the most costly storm in U.S. history, causing damage estimated at over $\$ 80$ billion and stopping economic activity in the region of New Orleans for an extended period. Nonetheless, its impact is essentially unobservable in U.S. GDP measures; Katrina made landfall in Louisiana on August 29, 2005, but GDP data continued their steady upward progression following this period without obvious interruption. ${ }^{1}$ As an alternative to these quarterly aggregate measures, therefore, this study investigates the use of electronic transaction data to improve our ability to monitor economic activity at relatively high frequencies or to learn about the effects of important events on economic activity.

Technological advances of the last several years have resulted in numerous forms of electronically-recorded data that have not yet been fully exploited by economic analysts. Check-out scanners in stores are probably the best known source of "new" economic data. A limitation of check-out data for macroeconomists, however, is that they are largely proprietary and so nationwide aggregations are seldom found, although limited aggregation of such data is often performed by external firms for the analysis of a specific product or industry. For this reason, scanner data are most often used in economics in the context of empirical industrial organization studies, e.g. Shankar and Bolton (2004). In macroeconomics, scanner data use has largely been limited to the assessment of overall price movements, e.g. Burstein, Eichenbaum and Rebelo (2005), Hausman and Leitbag (2004) and Silver and Heravi (2001, 2005). However Taylor (2009) uses scanner data to investigate sales through the period of the 2008 financial crisis. In the present study we consider further the potential usefulness of such electronically recorded transactions data for very short term macroeconomic event studies.

A distinct but related recent literature uses mixed frequencies (usually monthly and quarterly) of economic data to provide high-frequency (even daily) monitoring of the macroeconomy, incorporating new estimates of measured quantities on the day at which they become available; see in particular Evans (2005) and Aruoba et al. (2009). Such studies produce daily sequences of estimates of economic indicators,

\footnotetext{
${ }^{1}$ The values of U.S. real GDP, in billions of chained year-2000 dollars, seasonally adjusted at annual rates and rounded to the nearest integer, are 10946, 11050, 11086, 11217, 11291 for the quarters dated 01.04.2005 through 01.04.2006.
} 
but in general use measurements taken at a lower frequency; they are intended to incorporate efficiently new information arriving at different dates and frequencies, but not in general to trace the impacts of very transitory events which will show up to a very limited degree in monthly data. By contrast, the present study does not attempt full GDP measurement at the daily frequency, but does trace the impacts of extreme, transitory events through data which are limited in scope but measured daily with high accuracy. We do, in a separate study, also pursue the use of high-frequency data for short term modeling and forecasting of inflation, consumer expenditure and GDP growth, but the present paper concentrates on the use of these data for a new purpose. We provide a partial answer to a question on which very little evidence is available in existing macroeconomic literature: how can we trace the magnitudes and durations of effects of unusual events?

This paper, then, describes properties of some of the available payments system data and illustrates the use of debit card data to measure the short-term impact (in Canada, in this case) of three well-known events, at a daily frequency which would be unattainable using monthly or quarterly official data: in particular, we examine the September 11 terrorist attacks, the SARS epidemic of March-June 2003 and the August 2003 electrical blackout. We supplement the debit data with business-day frequency (typically five observations per week) payments system data, which contain information on the value as well as volume of debit and check transactions. The data are of interest in themselves; the next section describes them. The following section provides three short-term event studies. In each case we find impacts of the event which are moderate in size, and evidently of surprisingly short duration. These conclusions could not be reached with conventional, lower-frequency, macroeconomic data.

\section{Data and descriptive statistics}

We would want any potential high-frequency data source to be broadly defined, thereby capturing economic activity across sectors; to be available quickly; and to be measured accurately, with known transaction date (and, ideally, time of day). One such data source is electronic debit card purchases. Debit cards are a relatively new means of payment whereby a consumer can pay for a purchase by having funds directly withdrawn from his or her bank account. There are a number of benefits that we can identify with these data: a purchase made using a debit card results in an immediate rise in personal consumption expenditures, which is the largest component of GDP; debit card transactions are recorded instantaneously and electronically, thereby minimizing errors; at least in the case of Canada, a single entity (the Interac Organization) aggregates all transactions, so that reliable consumption statistics are available on a daily (and in principle higher) frequency. Note that we wish to distinguish actual purchases made with debit cards from cash withdrawals; the latter may be treated differently, since the funds withdrawn can be used for 
consumption at a later date.

We use two data sets: a daily data set comprising the total number (volume) of debit card transactions, and a business-day-only data set containing information on both volume and value of debit card transactions, small checks (under $\$ 50,000$ in value) and large checks. While the business-day data set contains more series, it has the important limitation that typically only five of the seven days in a week appear in the data. Each of these data sets pertains to Canada; debit cards are widely used in Canada, and account for over 10\% of nominal GDP and approximately 20\% of personal consumption expenditure. Debit purchases therefore provide a valuable high-frequency indicator of consumption expenditure.

\subsection{Daily debit transaction volume}

Data on Canadian debit card purchases record the exact date of the purchase; there is no problem of a potential time lag between purchase and recording of the purchase, as may arise with credit card data and certainly arises with check purchases.

In Figure 1a/b we plot total daily and monthly debit card transactions, as compiled by the Interac Organization; daily data are available from 1 January $2000 .^{2}$ Two features are apparent: (i) transactions exhibit a great deal of regularity, clear holiday effects, and a strong seasonal pattern, with relative peaks occurring in the second and fourth quarters, and troughs in the first and third quarters; and (ii) transactions have shown very rapid growth, greatly exceeding that of the real economy. While it is not apparent in the densely depicted data of Figure 1a, there are very strong day-of-week effects (the volume of debit transactions is highest on Fridays and Saturdays). The high variability around the Christmas holiday is visible in the daily data much more clearly than would be discernible in the monthly or quarterly aggregates usually available.

Clearly, in evaluating the impacts of important events we must be careful to make comparisons of cases with the same season, day of the week, holiday and so on.

\subsection{Business-day debit and check volume and value}

Business-day payments system data are reported only for Monday through Friday, excluding also public holidays. As a result, weekend and holiday transactions must be recorded with the data of a weekday, typically but not invariably Tuesday. We cannot therefore use these data to track every daily effect, but they remain useful in comparing the cumulative effects which we will also report below.

Our data set contains debit, small check and large check data, both value and volume, and begins in May 1998. The ability to compare value and volume gives

\footnotetext{
${ }^{2}$ In order to preserve the confidentiality of these numbers, the data are divided by a constant, which is not a simple power of 10 . The numbers on the vertical axis are therefore not meaningful, but relative sizes are preserved.
} 
additional insight into the interpretation of the daily Interac volume data presented above; Figures 2a-2c describe the joint distributions of volume and average value for each of the three means of payment.

Each of the Figures 2a-2c plots a joint density of volume of transactions per business day, and average value per transaction. ${ }^{3}$ The data plotted are residuals from a simple quadratic trend model with a dummy variable for days on which aggregated weekend or holiday transactions are reported; that is, for each series we compute the residuals from

$$
y_{t}=\alpha_{0}+\alpha_{1} t+\alpha_{2} t^{2}+D_{t}+\epsilon_{t},
$$

where $t=1,2, \ldots, N$ for sample size $N$.

The three means of payment display quite different patterns. For debit purchases, higher volume of transactions is clearly associated with higher average value per transaction; this may reflect larger volume and average value around holidays, for example. For small checks, there is some negative association, although there appears to be little association in the most concentrated region. For large checks, there is very little association between average value and volume (most of the probability mass is approximately parallel to the volume axis).

In analyzing specific events below, we will rely almost entirely on the debit data, for which the exact date of a transaction is known in the daily data. However, we will also display some results incorporating small check values. Large checks, exceeding $\$ 50,000$, have presumably little relation to normal consumer expenditures and we do not use the information on these amounts in the present study.

\section{$3 \quad$ Event analysis}

In each of the cases to follow, we match data from three years before and three years after an important event with the data from the year of the event itself. Because of the important calendar effects described earlier, we do not match the particular day of the month, but instead the nearest comparable day of the week and distance from a holiday. We present relatively unfiltered data; that is, we do not remove the holiday and day of week effects from the data. As in Taylor (2009), we present cumulative results, as well as daily values where available.

The results are presented graphically, in four panels (where feasible) for each case. The top row presents transaction volume results from the daily debit data, both daily and cumulative; the second row presents business day data. Because the business day data are available only five (or fewer) days per week, we do not present the daily data, but cumulative results only. The cumulative results in the lower two figures represent pure debit transaction values, and debit + small check transaction values. The lower-panel results therefore offer complementary information on

\footnotetext{
${ }^{3}$ Color represents height according to the usual convention; the density is estimated by kernel methods with bandwidth chosen by cross-validation.
} 
transaction values, with the limitation given by the lack of seven-day coverage. For cumulative results, this limitation is of less importance as all transactions do enter the series within a few days. In each case the year of interest is shown in red, the three preceding years in green, and the three succeeding years in blue.

To the extent that each period in the calendar year (each holiday and date) has unique features, conducting formal statistical inference on variability around particular dates would require a large number of yearly samples around these dates, to establish properties of distributions of economic quantities. Because we are limited to only about ten years of data, this is not feasible. However, one can obtain an indication of variability in the region of a date by examining neighboring years. In the event that an economic outcome in the year of an extreme event falls within the range of variability in neighboring years, then we may conclude that the event in question did not produce a change outside the range of normal variation. We will not be able to argue in the converse fashion: that is, we do not have sufficient sample information to conclude that an outcome outside the range of a few neighboring years is statistically significant. It happens nevertheless that the former inference can be drawn in a number of these cases.

\subsection{September 11, 2001}

The terrorist attacks of September 112001 had, of course, little direct impact in Canada apart from the diversion of some flights because of closed U.S. airspace. However, the magnitude and visibility of the attacks suggest a possible disruption of activity well outside directly affected areas.

September 112001 was a Tuesday, eight days after Labor Day. Considerable variation in the daily transaction total is visible in the vicinity of Labor Day, as Figure 3 indicates. In general, regular peaks in transactions occur on Fridays and troughs on Sundays. We match, in Figure 3, September 112001 with the Tuesdays following Labor Day by eight days in the neighboring years.

In the daily debit transaction volumes (panel A), there is a moderate but clearly discernible downward movement on September 11, which appears to be maintained through the next few weeks (panel B). The debit transaction values, however, show little evidence of an effect; debit+check transaction values are again outside the range of other years initially, with the difference tending to fade gradually over two weeks (recall that in the lower-panel business day results, a week consists of five days).

Overall, there is evidence of no more than a small, transitory effect on consumption. Even in the U.S., a retrospective assessment of the effects of the attacks (Makinen 2002) has suggested that the impact was minimal. However, this could not be discerned until some time afterward, underlining the value of daily data: policymakers need to monitor the impacts of extreme events in real time.

While, again, the events of September 11 had little direct or physical impact in Canada, the terrorist attacks were surely the most disturbing events of the decade, 
and this disturbing effect would have been felt throughout the country. It is noteworthy therefore that the effect on this consumption indicator is nevertheless modest.

\subsection{The blackout of August, 2003}

Around 4:00 pm on Thursday August 14, 2003, a power failure affected nearly 50 million households throughout most of Ontario and several U.S. states. Power was gradually restored over the next 48 hours, but the effect of the failure lingered for over a week as businesses and government were urged not to resume normal operations in an effort to conserve energy so as not to place stress on the fragile power grid. For example, many government workers in Ottawa did not return to work until 25 August. Holidays around this period in 2003 were observed on 4 August (Civic Holiday) and 1 September (Labor Day), where reductions in transactions are seen in each case. In the raw transaction data (not recorded here), an unusual change in the series evidently occurs on the first day of the blackout, 14 August. Transactions on this and subsequent days were slightly below the usual values that we typically observe on Thursdays (August 14) and Fridays (August 15); see Figure 4.

The pattern of impact that we observe is not dissimilar to that that we observe around September 11 2001. Despite the fact that this event was localized to one part of the country- comprising nonetheless a substantial proportion of the populationthere is a downward movement in daily debit transactions during the blackout days. Daily transaction volumes recover quickly thereafter, and there is no evident effect in cumulative daily transaction volume data after two weeks. In the cumulative debit value data, the initial days' values are outside the range of neighboring years, but the modest difference fades quickly. The combined debit+check value shows a more pronounced initial effect, no doubt reflecting difficulties in check processing through the blackout period. This difference also fades within two weeks.

\subsection{The SARS epidemic, March-June 2003}

Drache et al. (2003) provide a review of the events surrounding the SARS epidemic in Toronto through the period March-June 2003, and in particular of the media coverage which may serve as an indicator of the degree of urgency perceived by the public. This event differs from the previous two cases in being less 'acute'; although there were periods in which media coverage was particularly intense, the potential effect (as consumers might, for example, avoid public places) could have lasted through several months. We therefore present data over a ten-week interval, beginning with the first Monday in March, around which time media coverage began to be substantial.

Business day data from the payments system data set are missing for the month of April, 2003. The business day data therefore cannot be used for studying this period, and we restrict ourselves to the daily Interac transaction data. 
From Figure 5 we see that there is no detectable effect in these data. The large spikes in the daily transaction data are the Easter holiday period, and no other substantial events are visible. In the cumulative data, the year of the epidemic lies in the middle of the set of neighboring years. While concern about the SARS epidemic was to some degree localized to the region of Toronto, and to lesser degrees Vancouver and Montreal, it is nonetheless interesting that the scare had no observable impact on this measure of personal consumption activity.

\section{Concluding remarks}

This paper presents data sources and methods with which to answer questions concerning the impacts of extreme events, which cannot be answered with conventional macroeconomic data. The methods are illustrated with Canadian data, but data sources of this type are in principle generally available in developed economies.

Payments system data have a number of important features which make them potentially valuable in the study of macroeconomic events. Debit transaction data, in particular, can be matched precisely to the data of purchase and are in principle available the next business day, unlike standard macroeconomic indicators. The debit and check data examined here also cover a substantial proportion of consumer expenditure, although the addition of credit card transactions to the data set would enhance the coverage further. Among the other avenues for further research which these data suggest, incorporating daily credit card transaction data seems one of the most promising.

The data are used here to study three extraordinary events, each of which might be thought likely to have had a substantial effect on consumer activity. The remarkable feature of the results is that these events appear to have had only modest and transitory effects on personal consumption. While there is evidence of short term impacts in two cases, none of the cases show effects which remain clearly visible in a two-week cumulation.

This point underlines as well the fact that, if we wish to study impacts of such events, the usual monthly or quarterly data available from statistical agencies are unlikely to be of much value. By contrast, with payments system data, policymakers may be able to gauge the severity of unusual extreme events in a more timely manner, and may derive guidance as to measures required to dampen the impacts of negative events. 


\section{References}

[1] Aruoba, S. B., F. X. Diebold and C. Scotti (2009) "Real-Time Measurement of Business Conditions." Journal of Business and Economic Statistics 27, 417-427.

[2] Borzekowski, R., E.K. Kiser and S. Ahmed (2008) "Consumers' Use of Debit Cards: Patterns, Preferences, and Price Response." Journal of Money, Credit and Banking 40, 149-172.

[3] Burstein, A., M. Eichenbaum and S. Rebelo (2005) "Large Devaluations and the Real Exchange Rate." Journal of Political Economy 113, 742-784.

[4] Chevalier, J.A., A. K. Kashyap and P.E. Rossi (2003) "Why Don't Prices Rise During Periods of Peak Demand? Evidence from Scanner Data." American Economic Review 93, 15-37.

[5] Drache, D., S. Feldman and D. Clifton (2003) "Media Coverage of the 2003 Toronto SARS outbreak." Robarts Centre Research Paper, York University.

[6] Evans, M.D.D. (2005) "Where Are we Now? Real Time Estimates of the Macro Economy." International Journal of Central Banking 1, 127-175.

[7] Gerdes, G. R., J. K. Walton, M. X. Liu, D. W. Parke (2005) "Trends in the Use of Payment Instruments in the United States." Federal Reserve Bulletin 91 (Spring), 180-201.

[8] Hausman, J. and E. Leibtag (2004) "CPI Bias from Supercentres: Does the BLS Know that Wal-Mart Exists?" NBER Working Paper 10712.

[9] Humphrey, D. B., L. B. Pulley and J. K. Vessala (2000) "The Check's in the Mail: Why the United States Lags in the Adoption of Cost-Saving Electronic Payments." Journal of Financial Services Research 17, 17-39.

[10] Makinen, G. (2002) "The Economic Effects of 9/11: a Retrospective Assessment." Congressional Research Service, Library of Congress, Washington D.C.

[11] Shankar, V. and R. N. Bolton (2004) "An Empirical Analysis of Determinants of Retailer Pricing Strategy." Marketing Science 23, 28-49.

[12] Silver, M. and S. Heravi (2001) "Scanner Data and the Measurement of Inflation." Economic Journal 111, F383-F404.

[13] Silver, M. and S. Heravi (2005) "A Failure in the Measurement of Inflation: Results from a Hedonic and Matched Experiment Using Scanner Data." Journal of Business and Economic Statistics 23, 269-281.

[14] Taylor, J.D. (2009) "Analysis of Daily Sales Data During the Financial Panic of 2008." Working paper. 
Figure 1A

Daily data

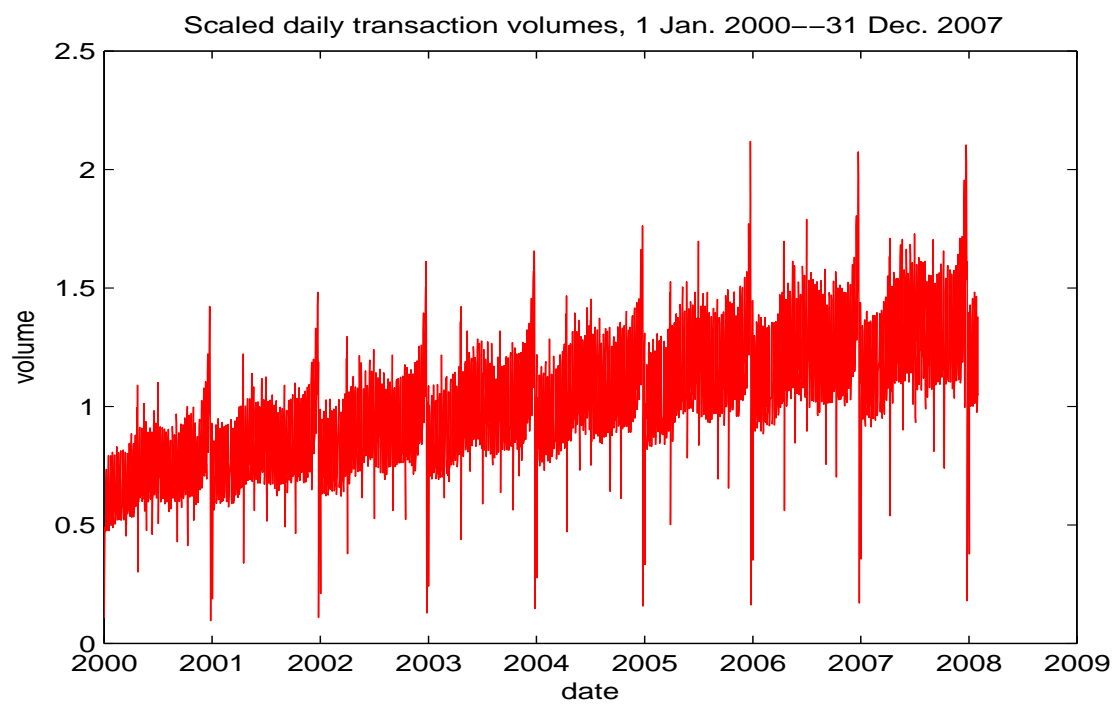

FiguRE 1B

Monthly aggregation of daily data

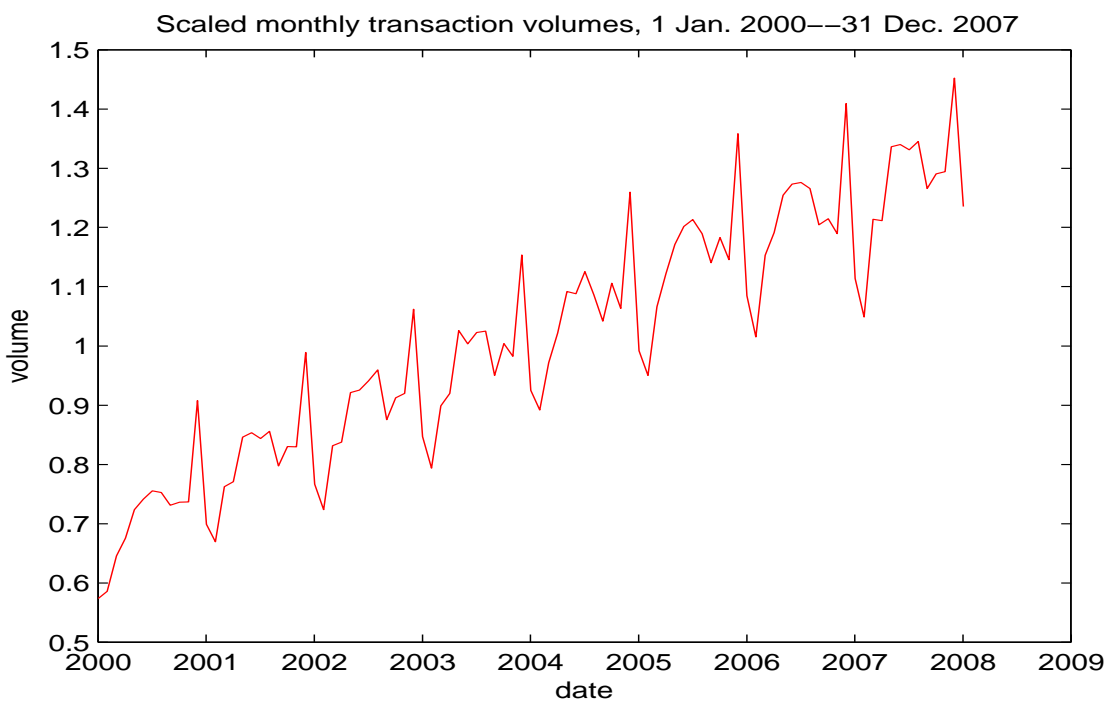


Figure 2A

Business-day data

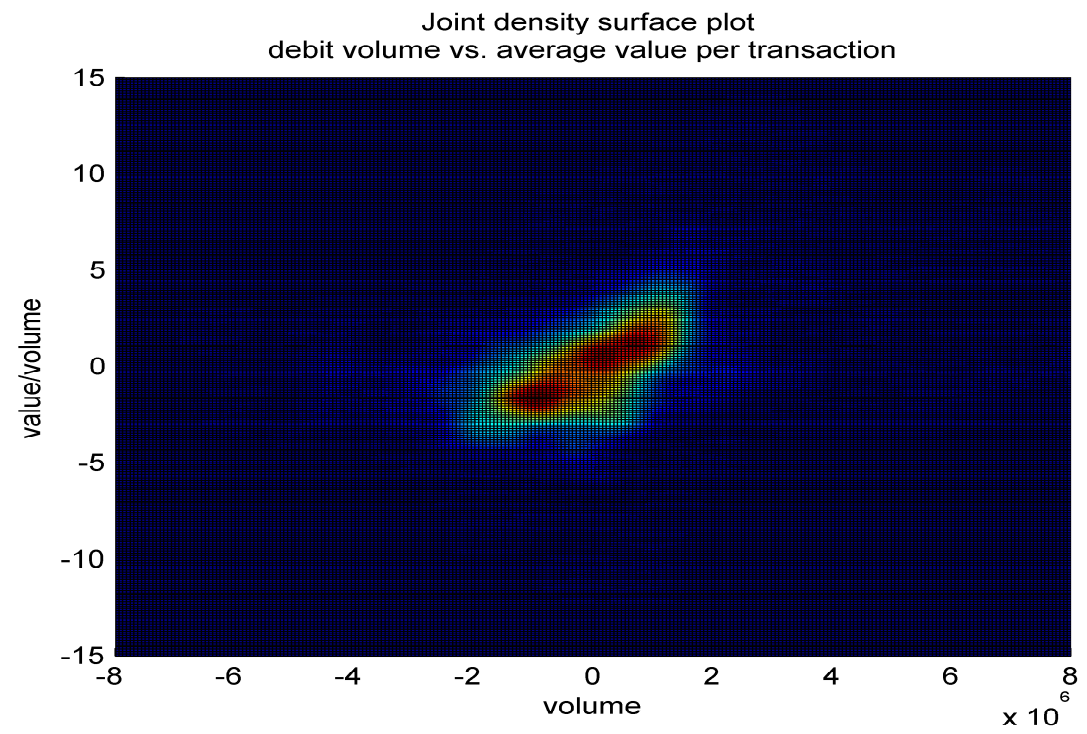

Figure 2B

Business-day data

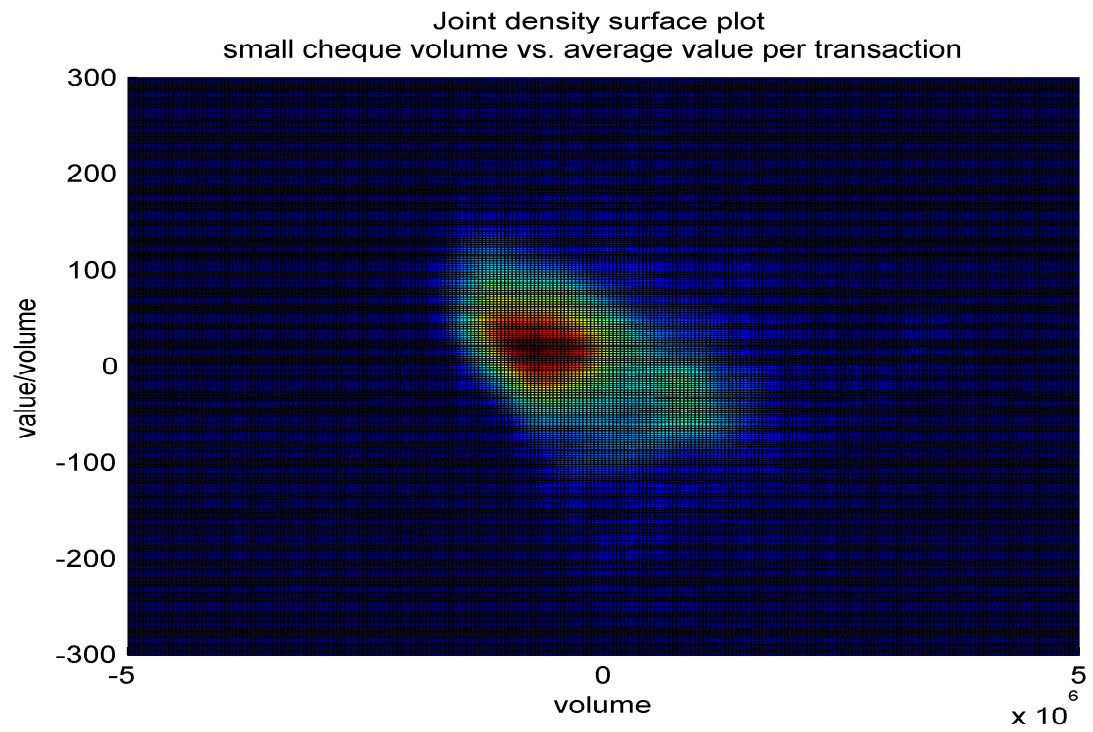


Figure 2C

Business-day data

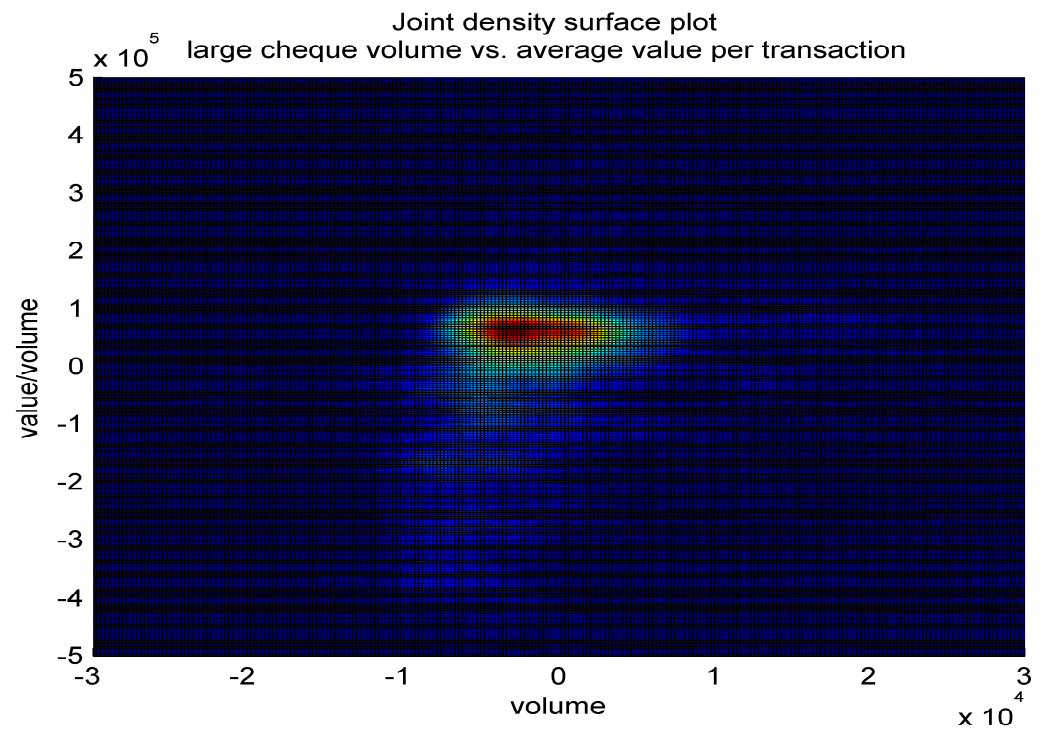


Figure $3^{4}$

September 112001 and comparable dates
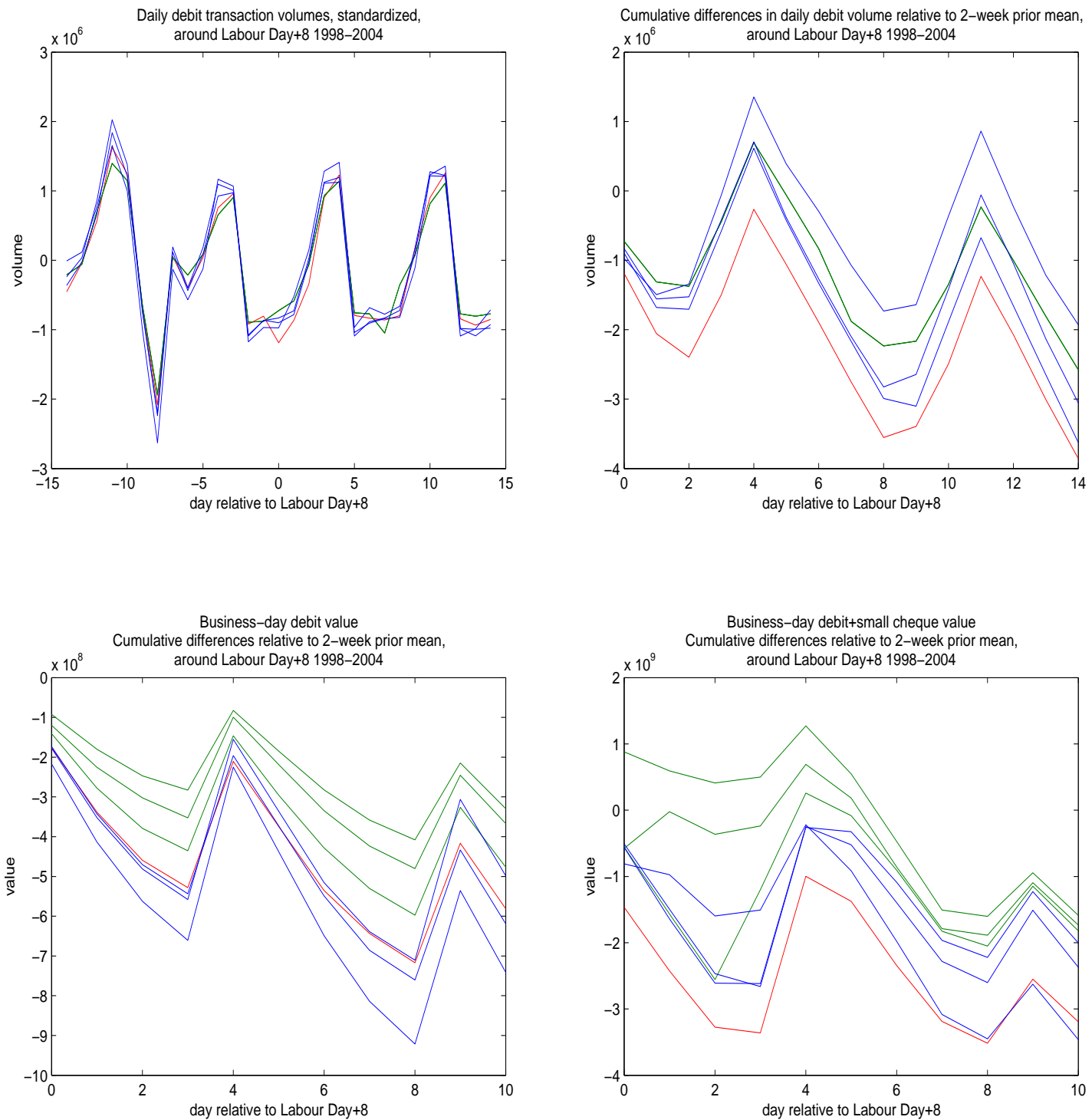

\footnotetext{
${ }^{4}$ Red line: 2001; green lines: year 2000 only in top panels, 1998-2000 in lower panels; blue lines: 2002-2004
} 
Figure $4^{5}$

August 2003 civic holiday and comparable dates
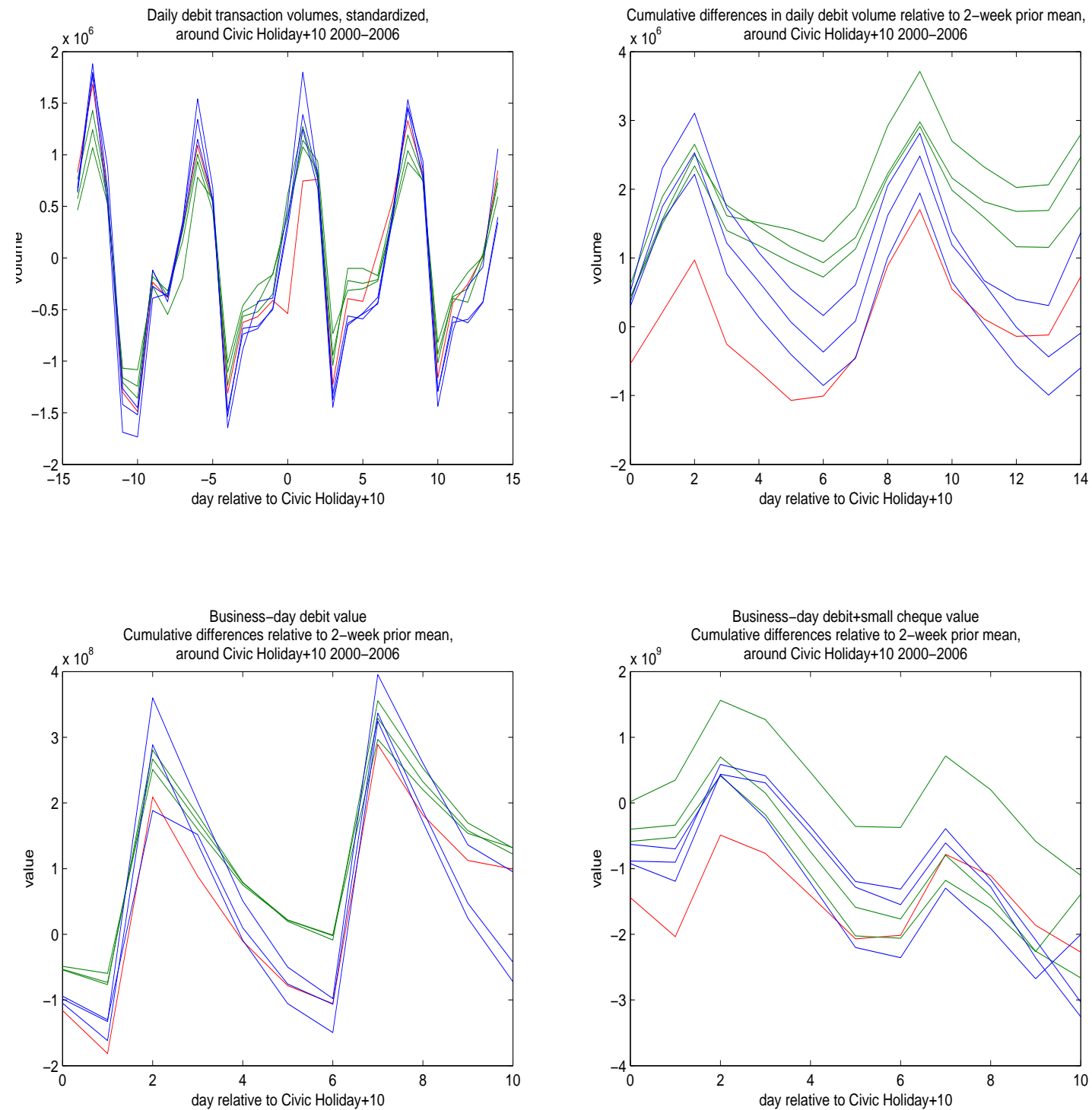

${ }^{5}$ Red line: 2003; green lines: 2000-2002; blue lines: 2004-2006 
Figure $5^{6}$

SARS epidemic and comparable dates
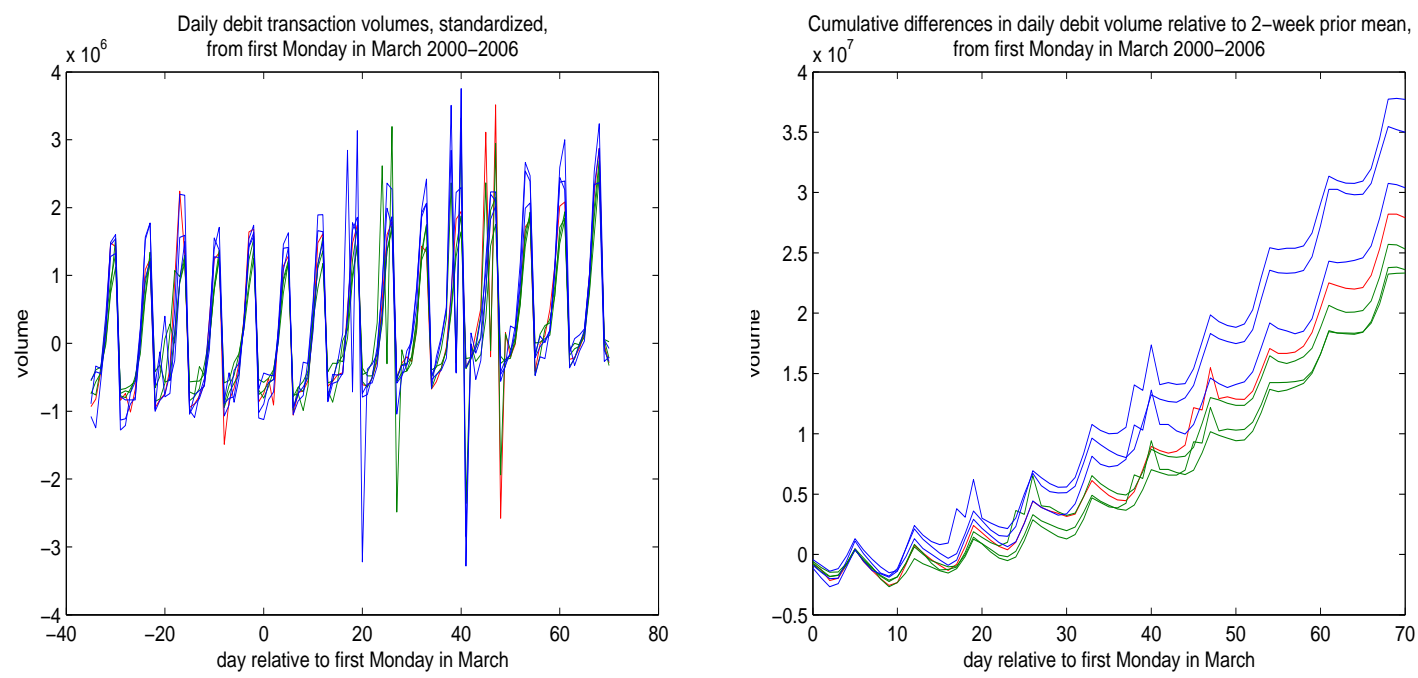

\footnotetext{
${ }^{6}$ Red line: 2003; green lines: 2000-2002; blue lines: 2004-2006
} 